\title{
Metaneumovirus humano en niños: primeros casos en Colombia
}

\author{
David Andrés Espinal ${ }^{1}$, Isabel Cristina Hurtado², Ana Eugenia Arango ${ }^{3}$, Josefina García ${ }^{4}$, \\ V. Alberto Laguna-Torres ${ }^{4}$, Sergio Jaramillo ${ }^{5}$ \\ Departamento de Pediatría, Hospital Pablo Tobón Uribe, Medellín, Colombia \\ 2 Departamento de Pediatría, Universidad Pontificia Bolivariana, Medellín, Colombia \\ 3 Grupo Inmunovirología, Universidad de Antioquia, Medellín, Colombia \\ 4 Departamento de Virología, Centro de Investigación de Enfermedades Tropicales de la Marina de los EE UU, \\ Lima, Perú. \\ 5 Departamento de Laboratorio, Hospital Pablo Tobón Uribe, Medellín, Colombia \\ El metaneumovirus humano es un nuevo patógeno asociado a infecciones respiratorias, principalmente \\ en niños, que produce cuadros clínicos que van desde leves hasta graves, los cuales pueden incluso \\ requerir tratamiento en unidades de cuidados intensivos. Hasta el momento, la reacción en cadena \\ de la polimerasa con transcripción inversa y el cultivo celular son los métodos más usados para su \\ diagnóstico. Se presentan los seis primeros casos de metapneumovirus humano en niños de Medellín, \\ Colombia.
}

Palabras clave: metaneumovirus, niño, infección del sistema respiratorio, informes de casos.

\section{Human metapneumovirus in children: first cases in Colombia}

Human metapneumovirus is a newly discovered pathogen associated with respiratory disease and occurring mainly in children. It produces an acute viral respiratory disease picture that varies from mild disease to severe, and which can require strict surveillance in intensive care units. Currently, reverse transcriptase polymerase chain reaction and cell culture are the most common methods for its diagnosis. The first six cases of human metapneumovirus in Colombia are presented from Medellín.

Key words: Metapneumovirus, child, respiratory tract infections, case reports.

\section{Introducción}

El metaneumovirus humano es un nuevo patógeno humano descubierto en 2001 como causa importante de infecciones de las vías respiratorias superiores e inferiores de niños. Este nuevo agente es un virus ARN perteneciente a la familia Paramyxoviridae, al igual que el virus sincitial respiratorio, subfamilia Pneumovirinae, género Metapneumovirus. En función de las secuencias genómicas que estos presentan, se han definido dos genotipos, $A$ y $B$, que, a su vez, se subdividen cada uno en dos subtipos: A1, A2 y B1, B2 (1-3).

Clínicamente, los niños infectados presentan sintomatología respiratoria que varía de leve

\author{
Correspondencia: \\ Sergio Jaramillo, Departamento de Laboratorio, Hospital Pablo \\ Tobón Uribe, Medellín, Colombia. \\ Teléfono: (574) 4459392 \\ sjaramillo@hptu.org.co
}

Recibido: 30/08/11; aceptado:11/02/12 hasta grave, en un síndrome clínico similar a la bronquiolitis producida por el virus sincitial respiratorio; en la radiografía de tórax de estos pacientes se puede observar una diversidad de imágenes con un amplio espectro, que puede ir desde la ausencia de imágenes patológicas hasta opacidades del espacio aéreo con tendencia a la consolidación (4). Estos signos y síntomas se confunden fácilmente con los de cualquier infección respiratoria, razón por la cual con frecuencia se subdiagnostica $(1,3)$.

El aislamiento del virus es difícil, ya que no crece en los medios de cultivo de los virus respiratorios habituales; requiere condiciones especiales y mayor tiempo para su crecimiento. A pesar de ello, el cultivo celular es ampliamente utilizado. Otros métodos disponibles para su diagnóstico son la reacción en cadena de la polimerasa con transcripción in-versa (RTPCR), la inmunofluorescencia directa y métodos serológicos como la prueba ELISA (5-7).

\section{Contribución de los autores:}

David Andrés Espinal, Isabel Cristina Hurtado y Sergio Jaramillo: recolección de datos y redacción del artículo. Ana Eugenia Arango: coordinación local, redacción y revisión crítica del artículo.

Josefina García y V. Alberto Laguna-Torres: realización de pruebas de laboratorio y revisión crítica del artículo. 
Actualmente, se cree que el virus tiene una distribución mundial; existen reportes del mismo en varios países, pero hasta ahora, no se había reportado ningún caso en Colombia, por lo que presentamos los primeros pacientes en edad pediátrica con infección respiratoria inferior causada por el metaneumovirus humano (MPVH) $(3,6,7)$.

\section{Materiales y métodos}

El Hospital Pablo Tobón Uribe, la Universidad de Antioquia y el Centro de Investigación de Enfermedades Tropicales de la Marina de Estados Unidos (Naval Medical Research Unit No. 6, NAMRU-6), con sede en Lima, Perú, han establecido una red de trabajo en Medellín para determinar la etiología y la circulación de los virus respiratorios productores de enfermedad de tipo influenza desde el año 2006.

El estudio fue revisado y aprobado por la Universidad de Antioquia y el Instituto Nacional de Salud de Colombia, de acuerdo con todas las regulaciones federales que protegen a los sujetos humanos.

\section{Población de estudio}

Incluye personas de cualquier edad con temperatura mayor o igual a $38{ }^{\circ} \mathrm{C}$, de inicio brusco, con odinofagia o tos, de cinco días o menos de evolución, con síntomas sistémicos o sin ellos, como mialgias, postración, cefalea o malestar general, que voluntariamente decidieran participar.

\section{Manejo de la muestra}

La toma de las muestras se hizo, en promedio, a los tres días de la enfermedad. A todos los pacientes se les practicó una prueba rápida para influenza $A$ y $B$ (Quickvue $^{\mathrm{TM}}$, Quidel, San Diego CA) en muestras nasales. La muestra de secreción faríngea para aislamiento viral se almacenó en tubos con medio de transporte (Universal Transport Media, UTM) los cuales se congelaban a una temperatura de $-70{ }^{\circ} \mathrm{C}$ y se enviaban en cajas con hielo seco al Departamento de Virología de NAMRU-6 en Lima, Perú. Localmente, en el Hospital Pablo Tobón Uribe, se hacían pruebas rápidas para detectar el virus sincitial respiratorio y Mycoplasma spp. La prueba que se usó para detectar el virus fue RapidSignal RSV Dipstrip ${ }^{\mathrm{TM}}$ (Orgenics, Germany) y, para Mycoplasma, ImmunoCard Mycoplasma ${ }^{\mathrm{TM}}$ (Meridian, Cincinnati, $\mathrm{OH}$ ).

\section{Procedimiento de laboratorio}

En el Departamento de Virología de NAMRU-6, las muestras de los hisopados faríngeos se sembraron en tres líneas celulares distintas: células MadinDarby de riñón canino (MDCK), así como células de riñón de mono verde (VERO) y células de riñón de mono rhesus (LLCMK2). Después de 10 días se pudo observar en los cultivos celulares el efecto citopático en las células infectadas y se practicó la prueba de inmunofluorescencia directa con anticuerpos monoclonales específicos contra metaneumovirus humano. A aquellas muestras positivas por inmunofluorescencia directa, se les aplicó la prueba de reacción en cadena de polimerasa para verificar el resultado positivo para metaneumovirus, utilizando sondas de ADN específicas para este virus (8). Las muestras fueron secuenciadas y las secuencias comparadas con secuencias conocidas de metaneumovirus publicadas en el GenBank.

\section{Reporte de casos}

En el cuadro 1 se resumen los síntomas y signos más importantes de los pacientes.

Paciente 1. Se trata de una niña de dos años y tres meses de edad, que consultó a urgencias por un episodio agudo de síndrome de dificultad respiratoria. Tenía como antecedentes de importancia que este era su cuarto episodio de infección pulmonar, por lo que se le diagnosticó una enfermedad pulmonar crónica.

Durante la evaluación inicial se encontró una paciente en regulares condiciones, con necesidad de oxígeno por saturaciones entre 84 y $89 \%$, taquipneica y con anormalidades a la auscultación pulmonar, por lo que se decidió hospitalizarla para manejo en el Servicio de Pediatría del Hospital Pablo Tobón Uribe.

Durante la hospitalización se le practicaron otros exámenes de laboratorio, entre los que se destacó una prueba ELISA para Mycoplasma pneumoniae con resultado positivo. Por el cuadro clínico y los anteriores resultados, se decidió iniciar tratamiento con claritromicina y medidas de soporte, entre las que se incluyeron suplemento de oxígeno, nebulizaciones con $\beta_{2}$ adrenérgicos, líquidos intravenosos y drenaje de secreciones pulmonares.

A pesar del hallazgo mencionado en los exámenes de laboratorio, se decidió continuar la exploración diagnóstica debido a la persistencia de saturaciones bajas de oxígeno con una leve mejoría clínica. La prueba rápida para influenza fue negativa y el cultivo viral se reportó como positivo para metaneumovirus humano. La paciente fue dada de alta a los nueve días de hospitalización con mejoría clínica. 
Cuadro 1. Principales hallazgos clínicos y de laboratorio de los pacientes con metapneumovirus humano

\begin{tabular}{|c|c|c|c|c|c|c|c|c|c|c|c|c|c|c|c|c|c|c|c|c|}
\hline 竞 & 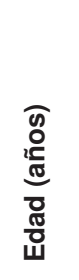 & ڤ & $\begin{array}{l}\frac{\pi}{5} \\
\frac{0}{0} \\
0 \\
0 \\
0 \\
\circ\end{array}$ & 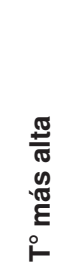 & 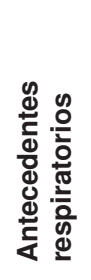 & 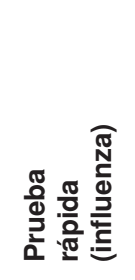 & $\stackrel{2}{\circ}$ & 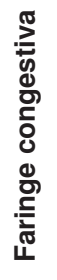 & 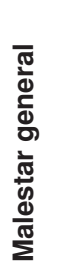 & 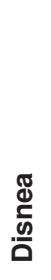 & $\frac{\frac{\pi}{2}}{\frac{0}{0}}$ & 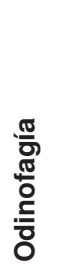 & $\frac{\pi}{\frac{\pi}{\pi}}$ & $\begin{array}{l}\frac{9}{0} \\
\frac{\pi}{0} \\
\frac{\pi}{0} \\
\frac{0}{\omega}\end{array}$ & 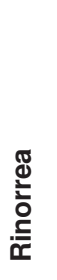 & 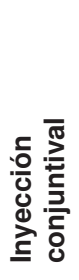 & $\begin{array}{l}\frac{\pi}{0} \\
\frac{0}{0} \\
\frac{0}{0} \\
\frac{0}{4}\end{array}$ & $\begin{array}{l}\text { 음 } \\
\text { 음 } \\
\text { 흠 } \\
\text { 음 }\end{array}$ & 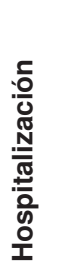 & 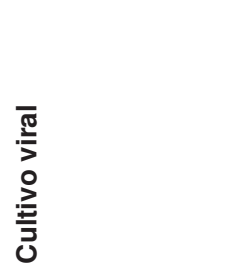 \\
\hline 1 & 2,25 & $\mathrm{~F}$ & 38,4 & 39 & Sí & Negativa & $x$ & $x$ & $x$ & $x$ & $x$ & & & & $x$ & & & & $x$ & $\begin{array}{l}\text { Metapneumovirus } \\
\text { Mycoplasma* }\end{array}$ \\
\hline 2 & 2,00 & $\mathrm{~F}$ & 36,7 & 39 & Sí & Negativa & $x$ & & $\mathrm{X}$ & & & $x$ & $x$ & $x$ & & & & & & Metapneumovirus \\
\hline 3 & 0,91 & M & 38,5 & 39,5 & Sí & Negativa & $x$ & & $x$ & & & & & & $x$ & $x$ & $x$ & $x$ & $x$ & $\begin{array}{l}\text { Metapneumovirus } \\
\text { Adenovirus } \\
\text { Virus sincitial } \\
\text { respiratorio * }\end{array}$ \\
\hline 4 & 9,00 & M & 37 & 39,5 & No & Negativa & $x$ & & $x$ & $x$ & $x$ & & & $x$ & & $x$ & & & & Metapneumovirus \\
\hline 5 & 6,00 & $\mathrm{~F}$ & 36,5 & 39 & No & Negativa & $x$ & $x$ & $x$ & & $x$ & $x$ & & & $x$ & & & & & Metapneumovirus \\
\hline 6 & 2,00 & M & 37 & 39 & No & Negativa & $x$ & $x$ & $x$ & & $x$ & & & & & & & & & Metapneumovirus \\
\hline
\end{tabular}

* El diagnóstico de Mycoplasma pneumoniae y de virus sincitial respiratorio se hizo en el Hospital Pablo Tobón Uribe.

Paciente 2. Se trata de una niña de dos años de edad, que consultó por tres días de evolución de fiebre, tos, coriza y disnea leve. Tenía como antecedentes personales importantes una infección respiratoria previa por M. pneumoniae (un mes antes del episodio), la cual se trató con claritromicina de manera ambulatoria, con evolución adecuada y sin otros antecedentes patológicos de importancia.

Fue evaluada en el Servicio de Urgencias del Hospital Pablo Tobón Uribe, donde le practicaron exámenes de laboratorio con resultados que se inclinaron hacia una infección viral y se le inició un ciclo de nebulizaciones con $\beta_{2}$ adrenérgicos. Al terminar el ciclo, la paciente mejoró clínicamente y no presentó nuevos episodios de hipoxemia, por lo cual se decidió dar de alta con medidas de soporte ambulatorias, con posterior evolución satisfactoria.

La prueba rápida para influenza fue negativa y el cultivo fue reportado como positivo para metapneumovirus humano.

Paciente 3. Se trata de un niño de 11 meses de edad, que ingresó al Servicio de Urgencias del Hospital Pablo Tobón Uribe por presentar dos días de evolución de tos, fiebre, dificultad respiratoria, baja saturación de oxígeno (saturaciones entre 85 y $88 \%$ ), malestar general, fotofobia, inyección conjuntival y decaimiento.

Por no presentar mejoría con el tratamiento instaurado en el Servicio de Urgencias y por tener antecedentes personales de síndrome recurrente de sibilancias, se decidió hospitalizarlo para manejo clínico y estudio.

La prueba rápida para influenza $A$ y $B$ dio negativa y una prueba de IFI para virus sincitial respiratorio fue positiva. El paciente presentó mejoría clínica importante, por lo que se le dio de alta al sexto día de hospitalización. El cultivo viral de este paciente fue reportado como positivo para adenovirus asociado a metaneumovirus humano.

Paciente 4. Se trata de un niño de nueve años de edad, sin antecedentes de importancia, que consultó por cuadro clínico de cuatro días de fiebre hasta de $39,5^{\circ} \mathrm{C}$, tos húmeda, sin dificultad respiratoria, astenia y malestar general.

Durante la evaluación médica le encontraron disminución del murmullo vesicular y crepitaciones en la base derecha. Se tomó una radiografía de tórax en la que no se observaron consolidaciones. Se estableció el manejo con nebulizaciones con $\beta_{2}$ adrenérgicos y antipiréticos. El paciente se recuperó completamente con manejo ambulatorio.

Se le practicó la prueba rápida para influenza A y B2, la cual fue reportada como negativa. El cultivo viral se reportó positivo para metapneumovirus humano.

Paciente 5. Se trata de una niña de seis años de edad, que consultó por un cuadro clínico de seis días de tos húmeda y disfonía acompañados de dos días de fiebre hasta de $39^{\circ} \mathrm{C}$, síndrome de dificultad respiratoria dado por taquipnea, 
retracciones subcostales, sibilancias bilaterales, sin crepitaciones ni cianosis.

La paciente tenía un diagnóstico previo de asma. La radiografía de tórax mostró infiltrados intersticiales. La prueba rápida para influenza $A$ y $B$ fue negativa, y el cultivo viral fue positivo para metaneumovirus humano.

Se hizo manejo médico con $\beta_{2}$ adrenérgicos nebulizados y esteroides inhalados. La paciente se recuperó completamente.

Paciente 6. Se trata de un niño de dos años de edad. Consultó por tos, fiebre, faringe congestiva, malestar general y astenia. La prueba rápida para influenza A y $B$ fue negativa. El cultivo viral fue reportado positivo para metaneumovirus humano. Se trató ambulatoriamente con recuperación completa.

\section{Discusión}

Los seis pacientes presentaron sintomatología de vías respiratorias inferiores y síndrome de dificultad respiratoria de leve a moderado, asociado a tos y taquipnea, fiebre alta que no mejoraba con las medidas habituales, y mialgias generalizadas; inicialmente, se les hizo el diagnóstico de bronquiolitis, neumonía o infección respiratoria aguda, lo que concuerda con los síntomas y diagnósticos diferenciales reportados en la literatura científica mundial $(2,3,6)$. Una característica clínica importante fue la acentuada hipoxia que presentaron algunos de nuestros pacientes, lo que se evidenció por las grandes necesidades de oxígeno durante la enfermedad, lo cual indicaba un compromiso intersticial. Posteriormente, la recuperación fue completa, únicamente con medidas de soporte (1).

En las radiografías de tórax de estos pacientes se observaron infiltrados intersticiales, los cuales son poco específicos y son las imágenes más comunes en pacientes con enfermedad de las vías respiratorias inferiores de origen viral, incluyendo la causada por metaneumovirus humano (3).

En uno de los niños se encontró infección concomitante con adenovirus y metaneumovirus humano por cultivo viral y, en una muestra cuatro días después, se detectó el virus sincitial respiratorio mediante prueba rápida. Existen varios estudios en los que se ha demostrado que puede presentarse la coexistencia de estos virus, pudiendo no tener manifestaciones adicionales o presentarse como una enfermedad de mayor seriedad. Se cree que el daño citopático producido por el virus inicial promueve la llegada y el crecimiento de otro virus e incluso bacterias $(1,2,6,9)$. Otro de los pacientes tenía antecedentes de infecciones de las vías respiratorias inferiores asociadas a M. pneumoniae $(3,6,7)$. Es importante destacar que estos dos pacientes sufrieron una infección más grave y tenían antecedentes de enfermedad pulmonar crónica de base.

La fiebre alta (mayor o igual a $39^{\circ} \mathrm{C}$ ) fue un síntoma predominante en todos los pacientes, así como también el malestar general. Los otros síntomas y signos variaron entre los pacientes.

Es de tener en cuenta que los pacientes eran menores de nueve años, pero cuatro de ellos tenían dos años o menos de edad. Estas edades son las de mayor prevalencia reportada en la literatura científica $(2,3,6)$, con un pico a los dos años que concuerda con la edad de tres de nuestros pacientes.

El diagnóstico de estos seis casos se hizo por medio de cultivo celular, seguido de inmunofluorescencia directa de las células del cultivo y de RT-PCR para confirmar el aislamiento. Estos virus también fueron secuenciados y los resultados se presentarán en otra publicación. El cultivo no es de amplia difusión y en nuestro país no se hace de rutina en hospitales y centros médicos. Se emplea básicamente en la investigación. Existen algunos métodos serológicos comerciales que son útiles para los estudios epidemiológicos. Podría pensarse en un futuro en el uso de la inmunofluorescencia directa sin cultivo celular previo, para lograr un diagnóstico rápido que luego podría confirmarse con la RT-PCR.

Aunque el presente reporte hace mención de seis casos encontrados de metaneumovirus humano, es importante señalar que debe reforzarse el diagnóstico por laboratorio de las infecciones respiratorias en las unidades de salud, dado que el uso indiscriminado de antibióticos puede favorecer la aparición de cepas resistentes bacterianas y es bien sabido que ellos no tienen ningún efecto sobre la infección viral.

Por lo tanto, si se refuerza el diagnóstico por laboratorio, a su vez se disminuirían los costos derivados de la utilización innecesaria de antibióticos. Las infecciones virales son causa frecuente de estas infecciones respiratorias altas, tal como se muestra en este artículo; sin embargo, el diagnóstico rutinario viral es costoso, pero, debido a su importancia, se establece en forma de vigilancia centinela a fin de poder determinar la circulación viral en un área geográfica. 
Los virus son causa frecuente de estas infecciones respiratorias altas, tal como se presenta en este artículo. En este estudio, la prueba rápida otorga el beneficio de un diagnóstico rápido, lo cual ayuda a evitar el uso inadecuado de antibióticos.

Debido a la presencia del virus en pacientes con infección respiratoria no complicada y sin antecedentes, es importante adelantar estudios para conocer la real prevalencia en nuestro país y validar métodos diagnósticos rápidos y costoefectivos (RT-PCR o serológicos), que ayuden a esclarecer la etiología y a orientar el tratamiento de nuestros pacientes.

\section{Conflicto de intereses}

Las opiniones y afirmaciones contenidas aquí son propias de los autores y no deben interpretarse como posición oficial o que reflejan la opinión del Ministerio de Salud de Colombia o del servicio naval de los Estados Unidos.

Los autores manifiestan que en este artículo no se presentan conflictos de intereses.

\section{Financiación}

La participación de NAMRU-6 fue financiada por la unidad de trabajo (Work Unit No. 84770582000 25GBB0016) dentro del estudio NMRCD.2002.0019 aprobado por el Comité de Ética del HPTU y del NAMRU-6.

\section{Referencias}

1. Casas I, Pozo F. Síndrome respiratorio agudo grave, gripe aviar e infección por metapneumovirus humano. Enferm Infecc Microbiol Clin. 2005;23:438-48.

2. Stockton J, Stephenson L, Fleming D, Zambon M. Human metapneumovirus as a cause of community-acquired respiratory illness. Emerg Infect Dis. 2002;8:897-901.

3. Williams J, Harris P, Tollesfon S, Halburnt-Rush L, Pingsterhaus J, Edwards K, etal. Human metapneumovirus and lower respiratory tract disease in otherwise healthy infants and children. N Engl J Med. 2004;350:443-50.

4. Heikkinen $T$, Österback R, Peltola V, Jartti T, Vainionpää R. Human metapneumovirus infections in children. Emerg Infect Dis. 2008;14:101-6.

5. Calicó I, Lowak M, Bas A, Betsebé M, Fuentes F, Loaiza M. Estudio comparativo de inmunofluorescencia directa, enzimoinmunoanalisis y cultivo para el diagnóstico de las infecciones por metapneumovirus humano. Enferm Infecc Microbiol Clin. 2009;27: 322-5.

6. Abara S. Metapneumovirus humano: un nuevo agente en IRA alta y baja. Neumol Pediatr. 2006;1:11-3

7. Qin Z, Qiang Y, Yao Z, Xiao-dong D. Seroprevalencia de infección por Metapneumovirus humano en children in Chongqing, China. Chin Med J. 2008;121:2162-6.

8. Bastien N, Liu L, Ward D, Taylor T, Li Y. Genetic variability of the $\mathrm{G}$ glycoprotein gene of human metapneumovirus. J Clin Microbiol. 2004;42:3532-7.

9. Fairchock, Martin E, Chambers S, Kuypers J, Behrens M, Braun L, et al. Epidemiology of viral respiratory tract infections in a prospective cohort of infants and toddlers attending daycare. J Clin Virol. 2010;49:16-20. 